\title{
Improved hippocampal dose with reduced margin radiotherapy for glioblastoma multiforme
}

\author{
Arif N Ali ${ }^{1,2^{*}}$, Tomi Ogunleye ${ }^{1,2}$, Claire W Hardy ${ }^{1,2}$, Hui-Kuo Shu ${ }^{1,2}$, Walter J Curran ${ }^{1,2}$ and lan R Crocker ${ }^{1,2}$
}

\begin{abstract}
Background: To dosimetrically evaluate the effect of reduced margin radiotherapy on hippocampal dose for glioblastoma multiforme (GBM) patients.

Methods: GBM patients enrolled on the Radiation Therapy Oncology Group (RTOG) 0825 trial at our institution were identified. Standard RTOG 0825 expansions were $2 \mathrm{~cm}+3-5 \mathrm{~mm}$ from the gross tumor volume (GTV) to the clinical tumor volume (CTV) and from the CTV to the planning tumor volume (PTV), respectively. These same patients also had reduced margin tumor volumes generated with $8 \mathrm{~mm}$ (GTV to CTV) $+3 \mathrm{~mm}$ (CTV to PTV) expansions. Individual plans were created for both standard and reduced margin structures. The dose-volume histograms were statistically compared with a paired, two-tailed Student's t-test with a significance level of $p<0.05$.

Results: A total of 16 patients were enrolled on RTOG 0825. The reduced margins resulted in statistically significant reductions in hippocampal dose at all evaluated endpoints. The hippocampal $D_{\max }$ was reduced from a mean of 61.4 Gy to $56.1 \mathrm{~Gy}(8.7 \%), \mathrm{D}_{40 \%}$ was reduced from $49.9 \mathrm{~Gy}$ to $36.5 \mathrm{~Gy}(26.9 \%), \mathrm{D}_{60 \%}$ was reduced from $32.7 \mathrm{~Gy}$ to 18.7 Gy (42.9\%) and the $D_{80 \%}$ was reduced from 27.3 Gy to 15.3 Gy (44\%).

Conclusions: The use of reduced margin PTV expansions in the treatment of GBM patients results in significant reductions in hippocampal dose. Though the exact clinical benefit of this reduction is currently unclear, this study does provide support for a future prospective trial evaluating the neurocognitive benefits of reduced margin tumor volumes in the treatment of GBM patients.
\end{abstract}

Keywords: Glioblastoma multiforme, GBM, Hippocampus

\section{Background}

Glioblastoma Multiforme (GBM) has traditionally been a devastating disease with median life expectancies of a year or less from the time of diagnosis [1]. In recent years, however, there have been several significant advances in the treatment and stratification of patients with GBM that have resulted in life expectancies in excess of 21 months for select cohorts [2]. Specifically, the combination of temozolomide and radiotherapy has increased the median survival from 12.1 months for radiotherapy alone to 14.6 months with temozolomide and radiotherapy [3]. More striking is the long-term follow-up data for temozolomide and radiotherapy, which reveals that $9.8 \%$ of

\footnotetext{
* Correspondence: aali24@emory.edu

'Department of Radiation Oncology, Emory University, 1365 Clifton Rd. NE, Atlanta, GA 30322, USA

${ }^{2}$ Winship Cancer Institute, Emory University, 1365 Clifton Rd. NE, Atlanta, GA 30322, USA
}

patients treated with concurrent therapy were alive at 5 years [4]. This point is further magnified when methylguanine methyl transferase gene (MGMT) methylation, which has been previously shown to be an independent prognostic indicator and predictor of benefit from temozolomide, is considered [2,5-8]. In those patients with MGMT methylation treated with a combination of temozolomide and radiotherapy the 5-year overall survival (OS) was shown to be as high as $13.8 \%$ [4].

Given the increased life expectancy of GBM patients in general and specifically those with MGMT methylation, attention has begun to focus on quality of life issues in addition to survival $[9,10]$. Multiple studies have demonstrated memory, learning, and other neurocognitive deficits in long-term survivors of GBM and other high grade gliomas previously treated with radiotherapy [6,9-17]. The retrospective review by Imperato et al. found that 2 out of 5 long-term high grade glioma survivors had 
significantly impaired short-term memory function [13]. Likewise, Lieberman et al. found that 2 out of 3 long-term astrocytoma survivors had diffuse cortical dysfunction so disabling that the patients could no longer work [14]. Perhaps the largest series was that by Peters et al. that found that out of 123 long-term GBM survivors with a median survival of 74.5 months, greater than $25 \%$ required the use of some psychoactive medications, thus indicating significant neurocognitive sequela [10]. It seems that the decreased neurocognitive performance of post-radiation glioma patients may be due, in large part, to memory dysfunction. Salander et al. evaluated 30 patients with malignant gliomas that had received radiation and found no clear impairment in global intellectual abilities or visual imagery, but did find a profound deficit in long-term memory [15].

It has been long known that the hippocampus is primarily involved with learning and long-term memory formation [18-23]. In primate studies, it was found that monkeys with bilateral removal of the hippocampus and amygdala had significantly impaired spatial learning and memory [24-26]. In patients, isolated lesions of the hippocampus have been consistently associated with anterograde amnesia and learning dysfunction [27-30].

Given the association of hippocampal lesions with memory dysfunction and the significant decline in neurocognitive performance after cranial irradiation, a study was performed that investigated the association of hippocampal radiation dose with neurocognitive impairment [31]. Gondi et al. found that a dose greater than 7.3 Gy to $40 \%$ of the bilateral hippocampus was associated with long-term impairment in Wechsler Memory Scale-Word List delayed recall for fractionated stereotactic radiotherapy treatment of benign or low-grade adult brain tumors [31]. With these results, there has recently been significant interest in minimizing dose to the hippocampus during whole brain radiation for the palliation of brain metastases and prophylactic cranial irradiation [32-35]. To date, however, there have been no explorations of hippocampal sparing in the setting of GBM even though neurocognitive decline appears to be just as significant after radiation for GBM and the life expectancy for a sizeable cohort of GBM patients is now the same or better than that for patients with brain metastases.

At our institution, we have previously reported the use of reduced margin radiotherapy in the management of GBM patients [36]. McDonald et al. found that use of total PTV margins of less than $1 \mathrm{~cm}$ resulted in radiographic tumor progression rates comparable with standard $2.3 \mathrm{~cm}$ to $2.5 \mathrm{~cm}$ GBM PTV margins. Specifically, $93 \%$ of the failures were in-field, further indicating that there was likely no recurrence detriment of a reduced PTV margin [36]. The purpose of the current study is to dosimetrically evaluate the effect of reduced margin radiotherapy for
GBM patients on hippocampal dose compared with standard margin radiotherapy and determine if there is likely to be a clinical benefit in terms of improved neurologic function based on previously published hippocampal radiation/neurocognitive toxicity dose thresholds [31].

\section{Methods}

\section{Patients}

Patients treated for glioblastoma multiforme at our institution and enrolled on the Radiation Therapy Oncology Group (RTOG) trial 0825 were identified. RTOG 0825 was a phase III trial of conventional concurrent chemoradiation and adjuvant temozolomide plus bevacizumab versus conventional concurrent chemoradiation and adjuvant temozolomide alone in patients with newly diagnosed glioblastoma [37]. A total of 16 patients, treated post-operatively according to RTOG 0825 were included in this analysis.

\section{Simulation and planning}

CT simulation scans were acquired with patients in the supine position using a thermoplastic head mask for immobilization and $3 \mathrm{~mm}$ CT slice thickness. Additionally, post-operative magnetic resonance images (MRI) were used for treatment planning purposes. The CT simulation image was registered to the MRI with the use of Velocity AI (Velocity Medical Solutions, Atlanta, GA) or Brainlab (Brainlab Inc., Westchester, IL) software. RTOG 0825 required both an initial planning target volume (PTV1) treated to 46 Gy in 23 fractions and a boost planning target volume (PTV2) treated to an additional 14 Gy in 7 fractions. In accordance with RTOG 0825 specifications, the T2 or FLAIR abnormality was expanded by a $2 \mathrm{~cm}$ margin to create the CTV1 and the T1 contrast-enhanced volume was expanded by $2 \mathrm{~cm}$ to create CTV2. Both CTV's were expanded by an additional $5 \mathrm{~mm}$ to create the standard margin PTV1 and PTV2. Normal structures (and dose constraints) required by RTOG 0825 were the lenses $\left(D_{\max }=7 \mathrm{~Gy}\right)$, retinae $\left(D_{\max }=50 \mathrm{~Gy}\right)$, optic nerves $\left(D_{\max }=55\right.$ Gy), optic chiasm ( $\left.D_{\max }=56 \mathrm{~Gy}\right)$ and brainstem $\left(D_{\max }=60 \mathrm{~Gy}\right)$. The left, right, and bilateral hippocampus were retrospectively contoured on the T1 post-contrast MRI and imported into the treatment planning software, Eclipse (Varian, Palo Alto, CA). Additionally, reduced margin CTV1 and CTV2 structures were created by expanding the FLAIR and T1 contrast-enhanced volume by $8 \mathrm{~mm}$, respectively. The reduced margin PTV1 and PTV2 were created by expanding the CTV's by an additional $3 \mathrm{~mm}$. Both the standard margin and reduced margin PTV's were planned using a sliding window IMRT technique with the RTOG normal tissue and target constraints of less than $10 \%$ inhomogeneity within the target volume and at least 95\% of the PTV receiving 100\% of the prescribed dose. 


\section{Statistics and analysis}

The primary means of comparing plans were dose-volume histograms (DVH). The appropriate dose and volume parameters for OAR were defined and used for comparison. Additionally, the $\mathrm{V}_{95 \%}$ and $\mathrm{V}_{98 \%}$ for PTV2 was used to assess target coverage. These parameters were statistically compared with a paired, two-tailed Student's t-test with a significance level of $\mathrm{p}<0.05$.

\section{Results}

Table 1 contains various PTV dosimetric parameters for both the standard margin and reduced margin plans. It is seen that volume receiving $95 \%$ of the prescribed dose $\left(\mathrm{V}_{95 \%}\right)$ is above $99 \%$ of the PTV for both the standard and reduced margin plans. It would be expected that there should be equal coverage of the PTV between the standard margin and reduced margin plans as target coverage is the effect of the equal PTV constraints imposed by the operator.

Though the standard margin and reduced margin PTV's received similar dose, it is seen from Table 2 that the reduced margin volumes translated to statistically significant reductions in all bilateral hippocampal dosimetric parameters. The reduction in dose varied from $5.3 \mathrm{~Gy}(8.7 \%)$ for the maximum dose to 12.0 Gy $(44.0 \%)$ for the $\mathrm{D}_{80 \%}$ with a $17.2 \mathrm{~Gy}(38.2 \%)$ reduction in the median dose. Additionally, as seen in Figure 1, there are similar reductions in dose with the reduced margin PTV's when the bilateral hippocampal structure is divided into individual left and right hippocampal structures.

\section{Discussion}

The current study confirms a statistically significant dosimetric reduction in hippocampal dose with the use of reduced margin radiotherapy. Specifically, it has been determined that the hippocampal dose reduction varies between $8.7 \%$ to $44.0 \%$ depending on the dosimetric parameter considered. Though a dose reduction of up to $44 \%$ to the hippocampus is quite significant in magnitude, it remains unclear whether there exists any translatable improvements in clinical memory function or other neurocognitive endpoints. The most recent study to explore the link between hippocampus dose and neurocognitive function is that by Gondi et al. [31] This study involved 29 patients with benign or low-grade brain tumors treated with fractionated stereotactic radiotherapy. Gondi et al. converted all doses to 2 Gy per fraction biologically equivalent doses and evaluated neurocognitive function with the Wechsler Memory Scale-III Word List. They found that a 2 Gy per fraction equivalent dose $\left(\mathrm{EQD}_{2}\right)$ to $40 \%$ of the bilateral hippocampi greater than $7.3 \mathrm{~Gy}$ was associated with impaired recall function. Additionally, they found a significant dose-response relationship with an of 14.9 Gy to the bilateral hippocampi and a slope of 0.540 . Though the hippocampal $\mathrm{D}_{40 \%}$ doses reported in the current study for both the standard margin PTV (49.9 Gy) and the reduced margin PTV (36.5 Gy) are above the 7.3 Gy threshold, this represents an approximately 13.4 Gy (26.9\%) reduction in the hippocampal $\mathrm{D}_{40 \%}$ dose. Assuming that the dose-response relationship observed by Gondi et al. continued to be linear with a slope of 0.540 , a $26.9 \%$ reduction in hippocampal $\mathrm{D}_{40 \%}$ dose should translate to a $14.5 \%$ improvement on the Wechsler Memory Scale-III Word Lists Delayed Recall at 18 months. In addition to Gondi et al., another group has reported a dose-response relationship for the radiation of the hippocampus in low grade or anaplastic gliomas [38]. Of course, with significantly limited cohort sizes and follow-up, the quantitative relationship between hippocampal dose and memory function reported by Gondi et al. and Mahajan et al. should be applied with an excess of caution and care $[31,38]$. However, the reduction of hippocampal dose with the use of reduced margins in GBM patients in the context of a potential dose-response relationship is still encouraging.

Factors that could potentially confound the previously observed relationship between hippocampal dose and neurocognitive effects would be secondary effects of systemic agents as well as direct neurocognitive effects of disease progression [39]. Hahn et al. evaluated patients that had not received any prior radiotherapy and found worse cognitive function in patients with left sided lesions and higher grade gliomas (GBM) [40]. This would indicate that, at baseline, there is some direct cognitive impairment from the intracranial disease. In fact, mental status on presentation has been found to be one of the most significant predictors of prognosis for malignant gliomas [41]. Additionally, it has been demonstrated that GBM patients

Table 1 Planning tumor volume (PTV2) dosimetric parameters

\begin{tabular}{|c|c|c|c|c|c|c|c|}
\hline \multirow[b]{2}{*}{ Parameter } & \multicolumn{2}{|c|}{ Standard margin } & \multicolumn{2}{|c|}{ Reduced margin } & \multirow[b]{2}{*}{ Difference } & \multirow[b]{2}{*}{ (\%) } & \multirow[b]{2}{*}{ p-value } \\
\hline & Mean & St. Dev. & Mean & St. Dev. & & & \\
\hline Max dose (Gy) & 63.59 & 0.96 & 63.60 & 1.13 & -0.006 & $-0.01 \%$ & 0.982 \\
\hline Mean dose (Gy) & 61.92 & 0.60 & 61.94 & 1.02 & -0.018 & $-0.03 \%$ & 0.934 \\
\hline V98\% dose (\%) & 99.47 & 0.70 & 99.47 & 1.36 & 0.006 & $0.01 \%$ & 0.982 \\
\hline V95\% dose (\%) & 99.81 & 0.37 & 99.72 & 0.81 & 0.089 & $0.09 \%$ & 0.596 \\
\hline
\end{tabular}


Table 2 Bilateral hippocampal dosimetric parameters

\begin{tabular}{|c|c|c|c|c|c|c|c|}
\hline \multirow[b]{2}{*}{ Parameter } & \multicolumn{2}{|c|}{ Standard margin } & \multicolumn{2}{|c|}{ Reduced margin } & \multirow[b]{2}{*}{ Difference (Gy) } & \multirow[b]{2}{*}{ (\%) } & \multirow[b]{2}{*}{ p-value } \\
\hline & Mean & St. Dev. & Mean & St. Dev. & & & \\
\hline Max dose (Gy) & 61.4 & 1.4 & 56.1 & 8.6 & 5.3 & $8.7 \%$ & 0.014 \\
\hline Mean dose (Gy) & 41.9 & 9.1 & 29.9 & 11.6 & 12.0 & $28.7 \%$ & $<0.001$ \\
\hline Median dose (Gy) & 45.2 & 17.2 & 27.9 & 15.6 & 17.2 & $38.2 \%$ & $<0.001$ \\
\hline D2\% (Gy) & 59.9 & 5.1 & 53.4 & 12.1 & 6.4 & $10.7 \%$ & 0.008 \\
\hline D20\% (Gy) & 57.6 & 8.5 & 46.1 & 16.8 & 11.5 & $20.0 \%$ & 0.001 \\
\hline D40\% (Gy) & 49.9 & 14.9 & 36.5 & 19.6 & 13.4 & $26.9 \%$ & $<0.001$ \\
\hline D60\% (Gy) & 32.7 & 13.5 & 18.7 & 10.9 & 14.0 & $42.9 \%$ & $<0.001$ \\
\hline D80\% (Gy) & 27.3 & 12.1 & 15.3 & 10.0 & 12.0 & $44.0 \%$ & $<0.001$ \\
\hline D98\% (Gy) & 20.7 & 9.3 & 11.8 & 7.7 & 8.9 & $42.9 \%$ & $<0.001$ \\
\hline
\end{tabular}

with tumor progression had more significant cognitive decline than patients with stable disease, though it was unclear whether this was due to disease progression or anti-epileptic use [42]. Anti-epileptic drug use has been previously implicated in the reduction of most cognitive functions except memory in a recent study on low-grade glioma patients [43]. Conversely, corticosteroids have been demonstrated to directly result in a decline in declarative and working memory [44]. Additionally, corticosteroids have been found to result in decreased hippocampal activity and blood flow [44].

While there are not yet enough data to fully dissect the specific contribution of radiation therapy to cognitive decline compared to systemic agents and disease progression, there is sufficient evidence to indicate that it is a

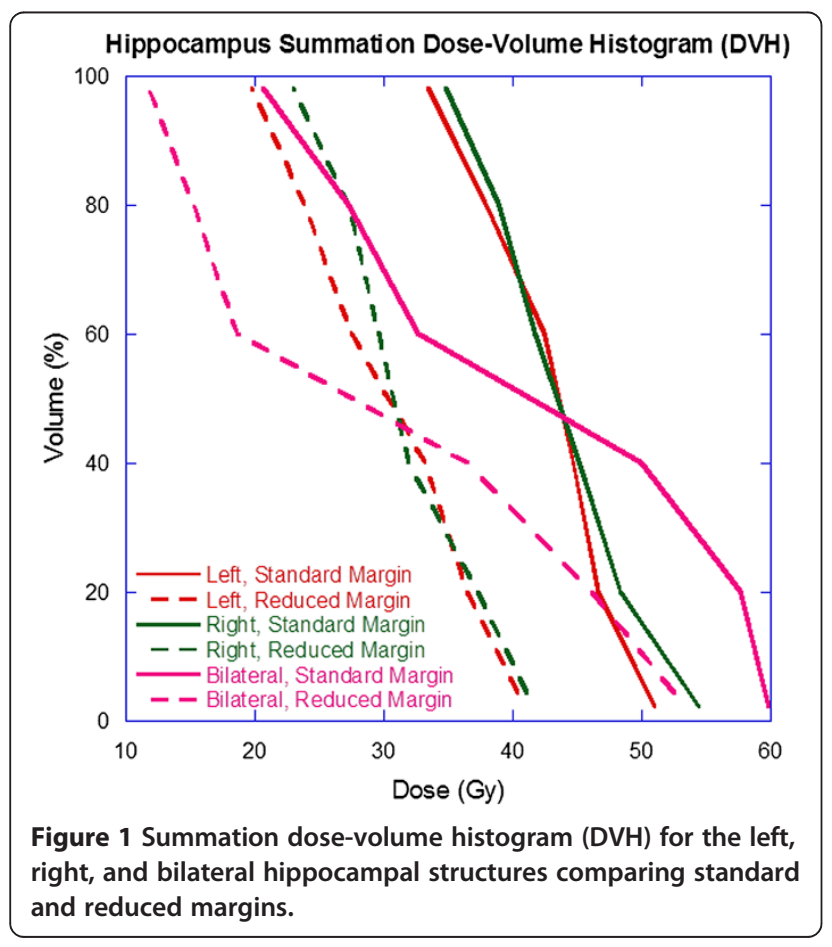

significant factor. As mentioned previously, there is currently significant interest in mitigating radiation-induced effects upon the hippocampus as a means to improve memory and other neurocognitive outcomes in long-term survivors with metastatic brain disease. The primary means of reducing radiation dose to the hippocampus has been to selectively avoid that structure with the use of IMRT. This is a reasonable approach for brain metastases as there is published evidence indicating that only $8.6 \%$ of patients have perihippocampal brain metastases and only $3.0 \%$ of brain metastases are perihippocampal [45]. In the current RTOG 0933 protocol studying hippocampal avoidance during whole brain radiation, the perihippocampal region is defined as the hippocampi with a $5 \mathrm{~mm}$ margin [46]. In the current RTOG 0825 protocol studying the use of bevacizumab in GBM patients, the PTV is defined as the GTV with a $2.3 \mathrm{~cm}$ to $2.5 \mathrm{~cm}$ margin. With such a large margin on the GTV, it would be difficult to selectively avoid the hippocampus in a majority of GBM lesions [37]. Using only the McDonald et al. reduced GBM margin of $1.2 \mathrm{~cm}$ from the GTV to the PTV (without selective hippocampal avoidance), this study has demonstrated up to a $44 \%$ reduction in dose to the hippocampus compared to standard RTOG margins. Additional hippocampal dose reduction may be expected with selective hippocampal avoidance in GBM patients. Though there is not yet an active hippocampal sparing protocol for GBM patients, the reduced margins from MacDonald et al. should safely enable hippocampal sparing in a greater proportion of GBM patients than standard margins [36].

A trial could conceivably be conducted to evaluate and quantify the neurocognitive benefits of reduced margin radiation therapy for GBM patients. Such a trial would likely require patients to be randomized between a standard margin arm $(2.3 \mathrm{~cm}$ to $2.5 \mathrm{~cm})$ and a reduced margin arm. Both arms would then receive identical Temodar treatment. The primary evaluated outcome would be neurocognitive function and the secondary outcomes would include radiographic progression, overall survival, and 
quality of life assessments. The hippocampus would be contoured as part of the trial and hippocampal dosimetric data from the treatment plan $\left(D_{\max }, D_{40 \%}\right.$, etc.) could then be correlated with late neurocognitive effects to generate further insight into the dose-response relationship of the hippocampal organ.

\section{Conclusions}

This study builds upon previously published data demonstrating the safety and efficacy of reduced PTV margins for GBM patients by dosimetrical evaluating and quantifying the effect of the reduced margins on hippocampal dose. It was found that a hippocampal dose reduction of $8.7 \%$ to $44 \%$ may be realized with the reduced PTV margins compared to standard RTOG 0825 margins for GBM patients. It is anticipated the reduced PTV margins will also allow selective hippocampal sparing in a greater proportion of GBM patients compared to standard margins. While the exact clinical benefit of this dose reduction is currently unclear, this study does provide support for a prospective clinical trial investigating the neurocognitive benefits of reduced margin radiotherapy and hippocampal sparing for GBM patients.

\section{Competing interests}

The authors declare that they have no competing interests.

\section{Authors' contributions}

AA: Organized and supervised the collection of data, performed the data statistical analysis, contoured the hippocampal structures, created all of the figures, and drafted the manuscript. TO: Performed the dosimetric calculations and generated the dosimetric plans. $\mathrm{CH}$ : Helped to collect and organize the data from the planning software to the spreadsheet for analysis. HS: Helped to draft and revise the manuscript. WC: Helped to draft and revise the manuscript. IC: Conceived of the study, participated in its design, and helped draft and revise the manuscript. All authors read and approved the final manuscript.

\section{Acknowledgments}

The authors would like to acknowledge the support of the entire physics and dosimetry section of the Department of Radiation Oncology at Emory University for their tireless work in the generation of these radiation delivery plans.

Received: 16 August 2013 Accepted: 26 December 2013

Published: 10 January 2014

\section{References}

1. Scott CB, Scarantino C, Urtasun R, Movsas B, Jones CU, Simpson JR, Fischbach AJ, Curran WJ Jr: Validation and predictive power of radiation therapy oncology group (RTOG) recursive partitioning analysis classes for malignant glioma patients: a report using RTOG 90-06. Int I Radiat Oncol Biol Phys 1998, 40:51-55.

2. Hegi ME, Diserens A-C, Gorlia T, Hamou M-F, de Tribolet N, Weller M, Kros JM, Hainfellner JA, Mason W, Mariani L, et al: MGMT gene silencing and benefit from temozolomide in glioblastoma. N Eng/ J Med 2005, 352:997-1003.

3. Stupp R, Mason WP, van den Bent MJ, Weller M, Fisher B, Taphoorn MJB, Belanger K, Brandes AA, Marosi C, Bogdahn U, et al: Radiotherapy plus concomitant and adjuvant temozolomide for glioblastoma. N Engl J Med 2005, 352:987-996.

4. Stupp R, Hegi ME, Mason WP, van den Bent MJ, Taphoorn MJB, Janzer RC, Ludwin SK, Allgeier A, Fisher B, Belanger K, et al: Effects of radiotherapy with concomitant and adjuvant temozolomide versus radiotherapy alone on survival in glioblastoma in a randomised phase III study: 5-year analysis of the EORTC-NCIC trial. Lancet Oncol 2009, 10:459-466.
5. Hegi ME, Diserens A-C, Godard S, Dietrich P-Y, Regli L, Ostermann S, Otten P, Van Melle G, de Tribolet N, Stupp R: Clinical trial substantiates the predictive value of 0-6-methylguanine-DNA methyltransferase promoter methylation in glioblastoma patients treated with temozolomide. Clin Cancer Res 2004, 10:1871-1874.

6. Krex D, Klink B, Hartmann C, von Deimling A, Pietsch T, Simon M, Sabel M, Steinbach JP, Heese O, Reifenberger G, et al: Long-term survival with glioblastoma multiforme. Brain 2007, 130:2596-2606.

7. Donson AM, Addo-Yobo SO, Handler MH, Gore L, Foreman NK: MGMT promoter methylation correlates with survival benefit and sensitivity to temozolomide in pediatric glioblastoma. Pediatr Blood Cancer 2007, 48:403-407.

8. Gerstner ER, Yip S, Wang DL, Louis DN, lafrate AJ, Batchelor TT: MGMT methylation is a prognostic biomarker in elderly patients with newly diagnosed glioblastoma. Neurology 2009, 73:1509-1510.

9. Schmidinger M, Linzmayer L, Becherer A, Fazeny-Doerner B, Fakhrai N, Prayer D, Killer M, Ungersboeck K, Dieckmann K, Marosi C: Psychometric- and quality-of-life assessment in long-term glioblastoma survivors. J Neurooncol 2003, 63:55-61.

10. Peters KB, Reardon DA, Vredenburgh JJ, Desjardins A, Friedman HS: NC-09. Characterization of long-term survivors of primary gliblastoma multiforme and their use of psychoactive medications. Neuro Oncol 2010, 12:iv58-iv61.

11. Archibald YM, Lunn D, Ruttan LA, Macdonald DR, Del Maestro RF, Barr HWK, Pexman JHW, Fisher BJ, Gaspar LE, Cairncross JG: Cognitive functioning in long-term survivors of high-grade glioma. J Neurosurg 1994, 80:247-253.

12. Hochberg FH, Slotnick B: Neuropsychologic impairment in astrocytoma survivors. Neurology 1980, 30:172.

13. Imperato JP, Paleologos NA, Vick NA: Effects of treatment on long-term survivors with malignant astrocytomas. Ann Neurol 1990, 28:818-822.

14. Lieberman AN, Foo SH, Ransohoff J, Wise A, George A, Gordon W, Walker R: Long term survival among patients with malignant brain tumors. Neurosurgery 1982, 10:450-453.

15. Salander $P$, Karlsson T, Bergenheim T, Henriksson R: Long-term memory deficits in patients with malignant gliomas. J Neurooncol 1995, 25:227-238.

16. Senger D, Cairncross JG, Forsyth PAJ: Long-term survivors of glioblastoma: statistical aberration or important unrecognized molecular subtype? Cancer J 2003, 9:214-221.

17. Taphoorn MJB, Klein M: Cognitive deficits in adult patients with brain tumours. Lancet Neurol 2004, 3:159-168.

18. Drachman DA, Arbit J: Memory and the hippocampal complex. II. Is memory a multiple process? Arch Neurol 1966, 15:52-61.

19. Levy DA, Manns JR, Hopkins RO, Gold JJ, Broadbent NJ, Squire LR: Impaired visual and odor recognition memory span in patients with hippocampal lesions. Learn Mem 2003, 10:531-536.

20. Milner B: Disorders of learning and memory after temporal lobe lesions in man. Clin Neurosurg 1972, 19:421-446.

21. Murray EA, Mishkin M: Severe tactual memory deficits in monkeys after combined removal of the amygdala and hippocampus. Brain Res 1983, 270:340-344.

22. Murray EA, Mishkin M: Severe tactual as well as visual memory deficits follow combined removal of the amygdala and hippocampus in monkeys. J Neurosci 1984, 4:2565-2580.

23. Scoville WB, Milner B: Loss of recent memory after bilateral hippocampal lesions. I Neurol Neurosurg Psychiatry 1957, 20:11-21.

24. Moser $\mathrm{E}$, Moser $\mathrm{M}$, Andersen P: Spatial learning impairment parallels the magnitude of dorsal hippocampal lesions, but is hardly present following ventral lesions. J Neurosci 1993, 13:3916-3925.

25. Malkova L, Mishkin M: One-trial memory for object-place associations after separate lesions of hippocampus and posterior parahippocampal region in the monkey. J Neurosci 2003, 23:1956-1965.

26. Squire LR: Memory and the hippocampus: a synthesis from findings with rats, monkeys, and humans. Psychol Rev 1992, 99:195-231.

27. Cummings JL, Tomiyasu U, Read S, Benson DF: Amnesia with hippocampal lesions cardiopulmonary arrest. Neurology 1984, 34:679.

28. Sidman M, Stoddard LT, Mohr JP: Some additional quantitative observations of immediate memory in a patient with bilateral hippocampal lesions. Neuropsychologia 1968, 6:245-254.

29. Mayes AR, Isaac CL, Holdstock JS, Hunkin NM, Montaldi D, Downes JJ, MacDonald C, Cezayirli E, Roberts JN: Memory for single items, word pairs, and temporal order of different kinds in a patient with selective hippocampal lesions. Cogn Neuropsychol 2001, 18:97-123. 
30. Zola-Morgan S, Squire L, Amaral D: Human amnesia and the medial temporal region: enduring memory impairment following a bilateral lesion limited to field CA1 of the hippocampus. J Neurosci 1986, 6:2950-2967.

31. Gondi V, Hermann BP, Mehta MP, Tome WA: Hippocampal dosimetry predicts neurocognitive function impairment after fractionated stereotactic radiotherapy for benign or low-grade adult brain tumors. Int J Radiat Oncol Biol Phys 2013, 85:348-354.

32. Gondi V, Tolakanahalli R, Mehta MP, Tewatia D, Rowley H, Kuo JS, Khuntia D, Tome WA: Hippocampal-sparing whole-brain radiotherapy: a "how-to" technique using helical tomotherapy and linear accelerator-based intensity-modulated radiotherapy. Int I Radiat Oncol Biol Phys 2010, 78:1244-1252

33. Gondi V, Tomé WA, Mehta MP: Why avoid the hippocampus? A comprehensive review. Radiother Oncol 2010, 97:370-376.

34. van Kesteren Z, Belderbos J, van Herk M, Olszewska A, Lamers E, De Ruysscher D, Damen E, van Vliet-Vroegindeweij C: A practical technique to avoid the hippocampus in prophylactic cranial irradiation for lung cancer. Radiother Oncol 2012, 102:225-227.

35. Prokic V, Wiedenmann N, Fels F, Schmucker M, Nieder C, Grosu AL: Whole brain irradiation with hippocampal sparing and dose escalation on multiple brain metastases: a planning study on treatment concepts. Int J Radiat Oncol Biol Phys 2013, 85:264-270.

36. McDonald MW, Shu HK, Curran WJ Jr, Crocker IR: Pattern of failure after limited margin radiotherapy and temozolomide for glioblastoma. Int J Radiat Oncol Biol Phys 2011, 79:130-136.

37. RTOG 0825 - phase III double-blind placebo-controlled trial of conventional concurrent chemoradiation and adjuvant temozolomide plus bevacizumab versus conventional concurrent chemoradiation and adjuvant temozolomide in patients with newly diagnosed glioblastoma. http://www.rtog.org/ClinicalTrials/ProtocolTable/StudyDetails.aspx? action=openFile\&FileID $=4664$.

38. Mahajan A, Dong L, Prabhu SS, Wang C, Yongbin Z, Zhang L, Meyers C, Woo S: Application of deformable image registration to hippocampal doses and neurocognitive outcomes. Neuro Oncol 2007, 9(4):583-584

39. Correa D: Neurocognitive function in brain tumors. Curr Neurol Neurosci Rep 2010, 10:232-239.

40. Hahn CA, Dunn RH, Logue PE, King JH, Edwards CL, Halperin EC: Prospective study of neuropsychologic testing and quality-of-life assessment of adults with primary malignant brain tumors. Int I Radiat Oncol Biol Phys 2003, 55:992-999.

41. Curran WJ, Scott CB, Horton J, Nelson JS, Weinstein AS, Fischbach AJ, Chang $\mathrm{CH}$, Rotman M, Asbell SO, Krisch RE, Nelson DF: Recursive partitioning analysis of prognostic factors in three radiation therapy oncology group malignant glioma trials. J Natl Cancer Inst 1993, 85:704-710.

42. Bosma I, Vos MJ, Heimans JJ, Taphoorn MJB, Aaronson NK, Postma TJ, van der Ploeg HM, Muller M, Vandertop WP, Slotman BJ, Klein M: The course of neurocognitive functioning in high-grade glioma patients. Neuro Oncol 2007, 9:53-62

43. Klein M, Engelberts NHJ, van der Ploeg HM, Kasteleijn-Nolst Trenité DGA, Aaronson NK, Taphoorn MJB, Baaijen H, Vandertop WP, Muller M, Postma TJ, Heimans JJ: Epilepsy in low-grade gliomas: the impact on cognitive function and quality of life. Ann Neurol 2003, 54:514-520.

44. Brown ES: Effects of glucocorticoids on mood, memory, and the hippocampus. Ann N Y Acad Sci 2009, 1179:41-55.

45. Gondi V, Tome WA, Marsh J, Struck A, Ghia A, Turian JV, Bentzen SM, Kuo JS, Khuntia D, Mehta MP: Estimated risk of perihippocampal disease progression after hippocampal avoidance during whole-brain radiotherapy: safety profile for RTOG 0933. Radiother Oncol 2010, 95:327-331.

46. RTOG 0933 - a phase II trial of hippocampal avoidance during whole brain radiotherapy for brain metastases. http://www.rtog.org/ClinicalTrials/ Protoco|Table/StudyDetails.aspx?action=openFile\&FileID=7493.

doi:10.1186/1748-717X-9-20

Cite this article as: Ali et al.: Improved hippocampal dose with reduced margin radiotherapy for glioblastoma multiforme. Radiation Oncology 2014 9:20.

\section{Submit your next manuscript to BioMed Central and take full advantage of:}

- Convenient online submission

- Thorough peer review

- No space constraints or color figure charges

- Immediate publication on acceptance

- Inclusion in PubMed, CAS, Scopus and Google Scholar

- Research which is freely available for redistribution

Submit your manuscript at www.biomedcentral.com/submit 